Arak, H. / Sosyal Bilimler Araştırmaları Dergisi. 2, (2007): 126-137

\title{
İkincil Yazının Oluşmasında Eleştirmenlerin Rolü Üzerine
}

\section{Hüseyin Arak ${ }^{\mathrm{a}}$}

\section{Özet}

$\mathrm{Bu}$ araştırma ikincil yazının oluşmasında eleştirmenlere düşen görevleri incelemektedir. Araştırma betimleme yolu ile yapılmıştır. Araştırmacı, eleştirmenlerin üstlendikleri görevleri; okur ile yazar arasında üstlendikleri sorumlulukları saptama amacını güder.

$\mathrm{Bu}$ araştırma sonucunda, eleştirmenlerin kaleme aldıkları tanıtıcı yazılar ve eleştirel incelemeler aracılığıyla hem okurlara hem de sanatçılara yol gösterici bir görev üstlendikleri tespit edildi. Edebiyatın gelişebilmesi için ikincil yazını oluşturan eleştirel incelemelerin gerekliliği anlaşıldı.

Anahtar sözcükler: ikincil yazın, eleştirmen, eleştiri, okur, yazar, sanatçı

\section{On the role of critics on the formation of the secondary literature.}

\begin{abstract}
In this research, the role of critics in the formation of secondary literature was investigated, using a descriptive method. The study is aimed at determining the factors that critics should bear in mind and the critics' responsibilities towards the writer and the reader.

The result of this critical research revealed that critics assume a duty of guidance both for the reader and the writer through their introductory work and criticisms. It has been understood that secondary literature consisting of critical research is essential for the development of Literature.
\end{abstract}

Key words: secondary literature, critic, criticize, reader, author, artist

\section{Giriş}

Kavram olarak eleştiri, "bir şeyin değerini vermek, o dünya içinde benzerlerine göre konumunu ve durumunu hükme bağlamak" demektir (Tural, 1993: 15). Bu görevi yerine getirenler ise genellikle teorik bilgiyle donanımlı olan edebiyat bilimciler ve eleştirmenlerdir. Onlar yeni çıkan eserlerin orijinal yönlerini göstermek, benzerleri arasındaki farkları, eksiklik ve aksaklıklarını değerlendirmek, eleştirmek, hükme bağlamak durumundadırlar (Tural, 1993: 14).

Edebiyat eleştirisi öncelikle, yazar-eser-okur arasındaki ilişkide önemli bir işleve sahiptir. Bunun nedeni eleştirmenin ortaya koyduğu inceleme yazısının eseri ve yazarı olduğu kadar okuru da yakından ilgilendirmesinde

${ }^{a}$ Yrd. Doç. Dr., Erciyes Üniversitesi Eğitim Fakültesi, Kayseri. 
yatmaktadır. Eleştirinin önemini ortaya koyan asıl öğe bu ilgi bağıdır. Okur açısından eleştirinin geçerli olup anlam kazanabilmesi için hiç olmazsa okurun önceden sahip olmadığı bilgileri vermesi ve okura belli bir görüş açısı getirmesi gerekir (Carlaui - Fillox, 1985: 25). İkincil yazını oluşturan eleştirel inceleme yazılarının, yazarları ve okurları yönlendirmede ve onların ufkunu açıp anlaşılmalarını sağlamada büyük önemi vardır.

$\mathrm{Bu}$ çalışmanın amacı, eleştirinin, incelemeci, aydınlatıcı, açıklayıcı ve değerlendirici yanıyla bütünlük sağladığı andan itibaren işlevini başarıyla yerine getirebileceğini ortaya koymaktır. Çünkü çağdaş edebiyat eleştirisi bu mantık üzerine kuruludur. Eleştirmen edebiyat eserini irdeleyen ve açıklayan eleştirel inceleme yazısıyla hem okura hem de sanatçıya hizmet etmektedir. Terry Eagleton'un da dile getirdiği gibi eleştiri, eserin muğlâklığını gidererek eseri tanıtmaya yönelik bir çabadır:

Eleştiri, anlatıdaki atlamaları, muğlâklıkları ve yoğunlaşma noktalarını (söylenmeyen kelimeleri, çok sık tekrarlanan kelimeleri, dil sürçmelerini, kekelemeleri) gözleyerek, ikinci gözden geçirmenin katmanları arasında gezebilir, tıpkı bilinçdışı istek gibi, eserin hem gizlediği hem de ortaya çıkardığı "altmetni” araştırabilir. Başka bir deyişle, yalnızca metnin söyledikleri ile değil, nasıl işlediği ile de ilgilenebilir (Eagleton, 2004: 222).

Ayrıca "eleştirinin artarak giden bir eğiliminin, ayrılmaz bir bütün sayllan eserleri ve yazarları daima daha derinden anlamaya çaba harcamak" olduğu görüşü ağırlık kazanmaktadır (Carlaui-Fillox, 1985: 99). Sanatsal bir ürüne yönelik eleştiriler bu bağlamda ele alınmalı, değerlendirilmeli ve belli bir bakış açısının süzgecinden geçirilmelidir. Bu nedenle eleştirmen sanat, din, politika, psikoloji, felsefe, tarih ve biyografi alanlarının hepsiyle yakından ilgili olmalıdır. Başarılı olmak isteyen titiz bir eleştirmen bu alanlarda mutlaka birikimli olmalı, kendisini yetiştirmelidir. Eleştirmenin başarılı bir eleştiri yapabilmesi için ciddi bir birikim yanında ele aldığı konu veya yazar hakkında ciddi bir araştırmaya da ihtiyacı vardır. Eleştirmen zengin bir bakış açısı ve kültüre sahip olursa, ancak o zaman ele aldığı konuyu, kişiyi veya eseri amacına uygun olarak değerlendirebilir. Böyle bir yaklaşımı kazanabilmesi için eleştirmenin kişisel duygulardan kurtulması bir gerekliliktir. Buna ek olarak eleştirmenin edebiyat yaklaşımlarına ve bilimsel yöntemlere aşina olması incelemesini verimli olarak ortaya koymasında yararlı olacaktır. Aksi halde 
kişisel tercihler, sempatiler ve belirli düşüncelere bağlanmış yazılar bilimsel yaklaşımı kazanmamış eleştirmen tarafından eleştiri gibi sunulabilir. $\mathrm{Bu}$ durumu Hilmi Uçan da şu sözleriyle özetler:

Yöntemli bir eleştiri, günümüzde bile tam anlamıla edebiyat alanındaki önemli yerini almıştır demek pek kolay değildir; yazınsal alanda önyargılar, pazarlama kaygıları, öznel düşünceler ön plandadır (Uçan, 2006: 33).

İyi bir eleştiri iyi bir sanat eseri gibi hayat ve insan ilişkilerine ait yeni bir yorum getirmedir. Eleştiride önemli olan, eleştirinin konusuna uygun bir yöntemle ve üslûpla yazılıp okurlara sunulmasıdır. Gürsel Aytaç eleştirel incelemeye konu olan eserin inceleme yönteminin konusu ve yazarın yaklaşımıyla uyumlu olması gerektiğini şöyle ifade eder:

Romanın, öykünün konusu, yazarının yaklaşımı, benim eleştiri yöntemimi büyük ölçüde belirliyor. Meselâ bir psikolojik romanı psikoloji, ama feminist romanı feminist eleştirinin kriterlerini göz önünde tutarak değerlendiriyorum.

Konuya uygun bir dil ve tavır geliştirmek, bakış açısını kaybetmemek, eleştirilen konu ve kişinin hakkında yeterli bilgiye sahip olmak başta gelmektedir. Murat Belge de bu konuyu irdelerken eleştirinin belirli bir yöntemle yapılmasından yanadır:

Eleştiri bir sistem gerektirir; daha önemlisi eleştiri "adına” yapacağımız bir değerler sıkalası gerektirir. Sanat ve edebiyat eleştirisi de, son analizde hayatın değerine ilişkin bir tartışma anlamına gelir (Belge, 2003: 790).

Eğer eleştirmen bir yönteme bağlı kalarak çalışmazsa yapılan hatalar yüzünden eleştiri niyetiyle yazılan yazı bazen amaçlananın dışına çıkabilmektedir. O zaman okurlara yarar sağlamaktan ziyade zarar verir.

\section{Eleştirmenin Görevi}

Çoğu insan övülmekten hoşlanır, ancak sıra eleştiriye gelince durum değişir. Kendisine gerçekleri göstermeye çalışanlara pek öyle iyi gözle bakıldığı söylenemez. Yazarlarda da durum bundan farklı değildir. Ortaya koyduğu eserde anlatmayı amaçladıkları eleştirmenler tarafından farklı anlaşılıp yorumlanırsa ortaya çıkan eleştirel inceleme yazar tarafından kabul görmez. Yazar anlaşılmadığını veya kendisine karşı düşmanca tavır takınılıp yıkıcı sarkastik eleştiri yapıldığını ortaya atar. Burada göz ardı edilen önemli nokta: 
Ortaya konan bir edebiyat eserinden herkes aynı anlamı mı çıarmalı, herkes aynı yorumda bulunmak zorunda mı sorusuna verilecek cevaptır. Her okurun ve eleştirmenin birikimine, kültürel alt tapısına göre bir anlam çıkarabileceği kabul edilmelidir. Bazen bu yazarın hoşuna da gitmeyebilir. Eleştirmenler yazılarını kaleme alırken amaçları yazarların hoşuna gitmek, onlardan aferin almak değildir. Onlar edebiyat anlayışlarına, eleştirel düşünce yapılarına göre bir inceleme ortaya koyarlar. Dolayısıyla eleştirmenlik yazarların ve okurların beğenisini kazanmak için yapılan bir meslek değildir.

Eleştirmenlerin içinde de haksız eleştiri yapanlar, belirli bir amaca yönelik güdümlü hareket edip öznel davrananlar bulunabilir. Kendi düşüncelerine yakın yazarlara öncelik verip, diğerlerine soğuk durabilirler. Bazı yazarları övüp okurların gündeminden inmemelerine katkıda bulunabilirler, ancak tüm eleştirmenlerin bu tutum ve davranış içinde olduğu elbette söylenemez. Gürsel Aytaç eleştirmen olarak etkinlik gösterirken herkese eşit davranmaya çalıştığını, takındığı eleştirmen tavrını ve yaklaşımını şöyle dile getirir:

Kaba çizgileriyle "soldan sağa" bütün yazarlarımızla ilgileniyorum. Bir eleştirmenin, bir araştırıcının görevi bence yargıcınki gibidir; taraflara yukarıdan bakabilmelidir. Öte yandan edebi eserin ölçüsü, neyin işlendiğinden çok nasıl işlendiğinde gizlidir. Bunu ortaya çıkarmak istediğinde, eleştirmen, ancak paletinde her renge yer verirse ülkenin edebiyat manzarasını yansıtabilir. Ben eleştirmeni, geleceğin edebiyat tarihçilerine malzeme hazırlamakla görevli sayıyorum.

Aytaç'ın sözlerinden de anlaşılacağı gibi eleştirmenin görevi taraf olmadan tüm edebiyat dünyasına tarafsızca yukarıdan bakabilmektir. Eleştirel incelemeler okurlar için sağlıklı bir kaynak oluşturması amacıyla yapılmalı ve okura eser hakkında olabildiğince nesnel bir yargıya varma olanağı sağlamalıdır. Edebiyat eleştirisinde eseri temel alan bir eleştiri çözümleyici bir inceleme sonunda, eserin sanatsal değerine ilişkin bir görüşü örneklendirecek ya da temellendirecektir. İnceleme sırasında eserle organik bağı korumaya özen gösteren bir eleştiri yaklaşımı pratik sonuçlar ortaya koyacak, eğer kuramsal sonuçlar elde edilir ise onlar da güvenilirlik kazanacaktır.

Edebiyat eleştirileri kaleme alan Füsun Akatlı eleştirmenin görevini ve etkinlik alanını şöyle tanımlar: 
Arak, H. / Sosyal Bilimler Araștırmaları Dergisi. 2, (2007): 126-137

Yaygın bir kanıya ve bu kanıya hak verdirebilecek kimi eleştiri yaklaşımlarına bakılırsa; sanatçı yapıtı koyar ortaya ve sonra sıra artık eleştirmene gelir. Onun görevi, her yapıtın üzerine ya balarısı gibi, ya akbaba gibi konmak ve yapitla okuyucu arasında iletken ya da yalıtkan bir 'eleştiri tabakası' oluşturmaktır. Ben sanmıyorum ki, gerçek bir sanatçının ya da kendini bilen okurun birbiriyle iletişim kurmak için böyle bir aracıya gereksinimleri olsun. Yazar, neyi nasıl yazması gerektiği konusunda direktifler almaya gereksinim duymayacağı gibi, ne dediğini okurlarına kendisinden daha iyi aktaracak, 'hislerine tercüman olacak' bir iyilikseveri de (!) tebessümle karşılayacaktır. Öyleyse nedir eleştirinin gerçek anlam ve işlevi? Ne olabilir? Eleştirinin amaçlarından biri; bir sanat görüşünü, yani bir sanat yapıtının sanatsal değerinin ölçütleri üzerine bir görüşü örneklendirmek ya da bir örnekten yola çıkarak çözümlemeler ve değerlendirmeler yapmak yoluyla böyle bir görüşü temellendirmek olabilir. ... Eleştiri için düşünülebilecek ikinci bir amaç da, ya tek tek yazın yapıtlarını ya da yapıtlarıyla bir yazarı ele alarak bir edebiyat incelemesi, bir tanıtma, ele alınan yapitlar arasında bağlantılar kurmayı ve bir sanat çizgisi belirlemeyi gözeten bir değerlendirme yapmak olabilir.

Eleştirel incelemeyi kaleme alan eleştirmen yazarlar arasında ayrım yapmamalı. Belli bir siyasi görüşün değil, çeşitli kesimlerin eleştirmeni olmalı ve edebiyatçı diye tanımlanan herkesin eserini iyi veya kötü olsun değerlendirmelidir. Eleştirmenlikte yan tutmamak, kapsayıcı olmak en başta gelen sorumluluklardan biridir. Bir yazara karşı takınılabilecek olan en olumsuz tavır onun eserini görmezden gelmektir. Böyle bir tutum yazareleştirmen ilişkisini yerici eleştirilerden daha kötü bir şekilde etkilemektedir. Bunun yanında, çeşitli grup dayanışmaları ile olmadık kitaplar okur karşısına büyük övgülerle çıkarıldığı için, okurun değer ölçütleri değersiz eserlerle sarsılmaktadır. Bu nedenle eleştirmenin iyi eserlerin seçiminde üzerine düşen görevin daima bilincinde olması gerekir. Eğer eleştirmen yaptığı uğraşının öneminin bilincinde olursa zorluklara da göğüs germeyi başaracaktır.

Eleştiri aynı zamanda çok büyük bir kültür, bilgi ve duygu birikimi isteyen bir alandır. Birçok yazarı ve kitabı eleştirmekle sorumlu olan eleştirmen, karşısında birbirinden farklı ürünleri bulmaktadır. Her yazarın bilgi düzeyi, felsefi anlayışı, yaşama bakışı ve diğer birikimlerinin farklı olduğu göz 
Arak, H. / Sosyal Bilimler Araştırmaları Dergisi. 2, (2007): 126-137

önüne alındığında kendisini nasıl zor bir görevin beklediğini unutmamak gerekir. Ele aldığı ürünlerin belki eser derecesine yükselmesine, ya da yok olup gitmesine katkıda bulunacaktır. Yeniliklerle ve sanatsal özelliklerle dolu, duygusal inceliklerle örülmüş eserleri kavramak, çözümlemek ve onları sahip olduğu kişisel duygularından sıyrılarak incelemek ve okurun önüne çıkarmak eleştirmenin başlıca görevlerindendir. Bu görevini yerine getirirken, asıl kalıcı olanın kendisi değil, eleştirdiği eser ve yazar olduğu bilinciyle hareket etmelidir.

Eleştirmenler bir taraftan okur olarak okuma eyleminde bulunurken, diğer taraftan da bunu okuma-yazma etkinliğine dönüştürmelidirler. Böylece eleştirmenler yazınsal yapıtı inceleme, çözümleme ve değerlendirme görevini de yerine getirmiş olurlar. $\mathrm{Bu}$ inceleme ve çözümlemeleri kaleme alırken eleştirmenin belirli bir inceleme yöntemini izlemesi gerekir. İnceleme yönteminin seçiminde ise ele alınan eserin içinde barındırdığ 1 gizil yanlarını açığa çıkaran bir yöntem tercih edilmelidir. Eleştirmenlerin eleştiri yöntemini nasıl seçtiğini ve eleştirilerini nasıl gruplandırabileceğini Berna Moran şu sözleriyle dile getirir:

Genellikle eleştirmen, kendi bilgisine, yeteneklerine, sanat anlayışına en uygun yöntemi esas yöntemi olarak benimser ve diğerlerinden de yararlanır. Hangi yöntemi kullanırsa kullansın bir eleştirmenin söylediklerini kabaca üç kategoriye ayırabiliriz: Betimleyici; açıklayıcı (yorumlayıc1); değerlendirici (Moran, 1999: 299)

Eğer eleştirmen incelemesinde belirli bir yöntemin ölçütlerine uyarak inceleme yapar, bir türde yoğunlaşırsa başarılı olur. Eleştirmenlerin incelemelerinde başarılı olamamaları büyük çoğunlukla bir türde yoğunlaşmamalarına, belirli ölçütler geliştirmemelerine, eleştirel alanda bilgi birikimine gitmemelerine, kendi aralarında aynı eser hakkında tartışmaya girmemelerine bağlanabilir. Yukarıda sayılan nedenler eleştirinin gelişmemesinin başlıca nedenleri arasında değerlendirilebilir. Bunun dışında eleştirmenlerin eleştirilerini kaleme alırken alacakları tepkilerden çekinmemeleri, korkmamaları da gerekmektedir. Eleştirmen alacağı tepkilerden rahatsızlık duymamalı, çünkü onun birilerine yaranmak gibi bir derdi olmaması gerekir. O sadece üzerine düşen inceleme, yorumlama ve tanıtma görevini yerine getirmelidir.

Edebiyat eleştirisi Türkiye'de henüz daha arzu edilen düzeyde olmasa da işlevini yerine getirmekte ve ikincil yazının oluşmasına katkı sağlamaktadır. 
Özellikle sanatçıyla okuru buluşturmaya çalışan eleştirmenler ile sanatçı yönü ağır basan eleştirmenlerin sayısı azımsanacak gibi değildir. Okurla sanatçıyı bir araya getirmeye çalışarak yaratıcı yönlerini eleştiri alanına yönlendiren sanatçılarımız da vardır. Muzaffer Buyrukçu'nun da dile getirdiği gibi, bu zor uğraşı Türkiye'de sürdürmeye çalışan eleştirmenlerimiz yok değildir:

Eleştiri, inceleme, deneme türlerinde ortaya koyduklarıyla o türleri ilginç kılan, isteklilerini çoğaltan, geliştirdikleri yöntemlerle, anlatım teknikleriyle ve takındıkları tavırlarla zenginleştirenlerin başında Nurullah Ataç, Sabahattin Eyüboğlu, Vedat Günyol, Memet Fuat, Fethi

Naci, Mehmet H. Doğan, Nermi Uygur, Akşit Göktürk, Füsun Akatlı vardır.

Yukarıda adı geçen eleştirmenler dışında Hilmi Uçan'a göre, Tahsin Yücel, Hilmi Yavuz, Mehmet Kaplan, Cemil Meriç, Asım Bezirci ve Ömer Lekesiz de bu eleştirmenler arasına ilave edilebilirler. Ona göre, bu eleştirmenler Cumhuriyet Dönemi'nde yazınsal eleştiri alanında okuyucuya ışık tutabilecek çalışmalar ortaya koyanlar arasında sayılabilir (Uçan, 2006: 34).

İkincil yazını oluşturan eleştirel incelemelerin Türk edebiyatında henüz istenilen düzeyde yeterince gelişmediği görülse de, eleştirmenler özverili çalışmalarıyla yeni eserleri tanıtıcı yazılar kaleme almaktadırlar. Olumsuzluklar içinde çalışmalarını sürdürmek zorunda kalan eleştirmene hep kötü gözle bakıldığından, eleştirel incelemeye girişmek büyük bir cesaret istemektedir. Bu nedenle sadece nitelik olarak değil, aynı zamanda nicelik olarak da eleştirel içerikli çalışmalar sınırlıdır. Yeterince eleştirel içerikli inceleme yapılmaması sorunların en başında gelmektedir. Örneğin, Alman Edebiyatında eleştiriye ve incelemeye dayalı olan ikincil yazın oldukça gelişmiş durumdadır ve yayımlanan eserlerin çok farklı açılardan incelemeleri yapılmaktadır. Oysa Türk Edebiyatında batılı eserlerle boy ölçüşebilecek özelliklere sahip birçok eser olmasına rağmen, bu eserlerin yeterince incelemesi yapılmadığından ikincil yazın gelişmemekte ve böylece eserlerin tanıtımı gerçekleşmediği gibi iyi anlaşılmalarının da sağlanamadığı görülmektedir.

Eleştirel içerikli yazılarda eleştirmen sanatçıyı suçlayıcı, yerici ve yerle bir edici yaklaşım içinde bulunmamalıdır. Böyle bir yaklaşım eleştirinin olumsuz anlamda değerlendirildiğini belgelemektedir. Oysa eleştiri sadece yermek değil, aynı zamanda bilimsel bir yaklaşımla eserin gizil yanlarını açığa çıkarmak, okur için daha anlaşılır hale getirmektir. Bunun yanında eleştirmen 
eleştiriye saygıyla bağlanmalı, aksi halde bu uğraşı başka türlü sürdürülemez. Çoğu kez karşılık almadan sürdürülen bir uğraş belirli bir noktadan sonra son bulacaktır. Maddi refaha ve üne kavuşturmayan eleştiri birçok defa eleştirmeni sevdiği birçok insanla olumsuz eleştirilerinden dolayı karşı karşıya da getirir. Tüm bu olumsuzluklara rağmen eleştirmenin eleştiriden vazgeçmeyerek sürdürmesi gerekir. Çünkü düşünceye saygı ve düşünsel çalışmaya eğilim ancak eleştiriyle kendini dışa vurabilir. Eleştirel içerikli yazılar yazmaya başlayan kişi çileli, riskli ve aynı zamanda cesaret isteyen bir uğraş alanı içinde bulunduğunu bilmelidir.

Gerçekçi bir eleştirmen algılama ustası olarak sadece sanatı ve sanatçıyı tanıtan kişi değildir, aynı zamanda sanatı ve sanatçıyı özel kılan koşulları saptar. Bilinçli tavır alarak belirli bir sanat olayı karşısında kendi yargısını dile getirir. Eleştirileriyle yeni yayımlanan eserleri inceleyip yorumlaması gereken eleştirmen, yargılar getirirken cesareti kadar engin bir kültürel altyapıya da sahip olmalıdır. Okurların tepkisinden çekinip basmakalıp eleştirmenliğe yönelenler zamanla yok olup giderler. Bugün artık eleştirmen kullandığı eleştiri yaklaşımı ve yönteminden sorumludur; kendisine eleştirisi ile ilgili yöneltilen sorulara, kaynak ve kanıt göstermeksizin kurnazlığa kaçan cevaplar verememektedir. "Bence böyle, bundan dolayı" gibi sadece öznel algılama sözcükleri içeren ve sağlam dayanağı olmayan eleştiriler ve yargılar kabul görmemektedir. Eleştirmen incelemesi sırasında dile getirdiği yorumlarını sağlam kanıtlara dayandırmak zorundadır. Edebiyat eserinin içerdiği sanatsal değerleri ortaya çıkarıp okura örnek bir okuma varyasyonu sunan, okura kendi alımladığını ileten eleştirmen Hilmi Uçan'ın da vurguladığı gibi farklı bir göreve sahiptirler:

Bir yazarın görevi "yazmaktır": Canının istediğini yazar, "keyfi" davranabilir. Ama okuyucu/eleştirmenin "keyfilik ve "ilkesizlik" gibi bir lüksü yoktur. Okuyucu/eleştirmen sövmek, övmek, "gagalamak" peşinde olamaz: Önce anlamak, sonra anlatmak, anlamlandırmak, değerlendirmek durumunda (Uçan, 2003: 12).

$\mathrm{Bu}$ görevinin dışında eserin edebiyat içindeki yerini almasında söz sahibi olan da yine eleştirmendir. Yıldız Ecevit'in de önemle üzerinde durduğu gibi, eserin edebiyatta yer edinebilmesi için öncelikle eleştirel olarak incelenmesi, okurlara tanıtılması ve böylece ikincil edebiyatın içinde yer alması bir gerekliliktir: 
Arak, H. / Sosyal Bilimler Araștırmaları Dergisi. 2, (2007): 126-137

Bir edebiyat ürününün değerinin kantlanabilmesi için zamana gereksinim vardır. Avangart biçim denemelerinde bulunan ve nonkonformist bir yap1 gösteren yazarın, edebiyat çevreleri tarafından benimsenmesi için gereken süre ise her zaman daha uzun olmuştur. Örneğin, yalnız Alman değil, dünya tiyatrosunun öncü isimlerinden Büchner'in edebiyat tarihi içinde yerini alması, ölümünden 50-60 yıl sonra gerçekleşebilmiştir. Bir yazarın toplum tarafından benimsenmesi için, her şeyden önce okunması, yapıtlarıyla ilgili olarak yayımlanan eleştiri yazıları ve araştırmalarla değerinin kanıtlanması -en azından Batı toplumunda bu böyledir-, bunun için ise süreçlerin büyük bir hızla yaşandığı çağımızda bile en az 10-15 yılın geride bırakılması gerekir.

Eserlerin inceleme sonucu değer kazanıp kazanmaması uzun bir süreçten sonra kesinlik kazanmaktadır. Bu süreci belirleyen ikincil yazında eser hakkında çıkan inceleme ve değerlendirme yazılarıdır. İkincil yazını oluşturan eleştirel incelemeler eserin edebiyat dünyasına getirdiği yeni anlatım öğelerini ve biçimlerini ortaya koymaya çalışır. Buradan yola çıkarak eleştirmenlerin eleştirel incelemelerini okura ulaşan küçük ama sağlıklı ipuçları olarak değerlendirmek yerinde olur. Okur ile yazarı buluşturup bir araya getiren eleştirmen köprü görevi görmektedir. Eleştirmenlerin inceleme yazısı yazmasıyla yeni eserlerin değerlendirme süreci sağlıklı olarak işler. Böyle bir durumda eserler okurla buluşarak bir köşeye atılıp yok olup gitme tehlikesiyle karşı karşıya kalmazlar.

Bir edebiyat eseri tamamlanıp yazarının elinden çıktığında onu okurlara ulaştıracak, ya da anında değerini küçültüp yok olup gitmesini sağlayacak olan eleştirmen görevinin ve sorumluluğunun bilincinde olmalıdır. $\mathrm{Bu}$ nedenle eleştirmenin görevi küçümsenmemeli, eleştirmenliğin çok önemli bir etkinlik alanı olduğu bilinmelidir. Eleştirmenlere gereken saygı gösterilmeli ve edebiyat dünyasında taşıdıkları önem iyi anlaşılmalıdır, çünkü bir yapıtın içerdiği sanatsal öğeleri ortaya çıkaracak, onları okura iletecek olan eleştirmendir. Henüz daha eser katına yükselmeyen yapıtın hangi gelenekte ve hangi akımların etkisi altında olduğuna ve çağdaş anlatım tekniklerini içerip içermediğine, bir yenilik getirip getirmediğine karar verecek olan eleştirmendir. Eleştirmenin bu tür yorumlarıyla birlikte yapıt tartışmaya açılmış ve derin incelemelere alınmış olur. 
Eleştirmen beğendiği eseri geniş halk kitlelerine ulaştırır ve okur çevresinin genişlemesine katkıda bulunur. Böyle bir katkı, ancak iyi eleştirilerin ortaya çıkmasıyla sağlanabilir. İyi eleştirilerin ortaya çıkabilmesi de iyi eleştirmenlerin bu alanda etkinlik göstermesine bağlıdır. Eleştirel incelemelerin değerli edebiyat eserlerini ortaya çıkarmanın yanında ait olduğu toplumun kültürel yapısına bir katkı sağladığı da göz önünde bulundurulmalıdır. Yazarın ülkesinin diline kattığı zenginlik eleştirel incelemeler aracılığıyla açığa çıkarılır. Eleştirinin bir anlama uğraşı, iyiyi kucaklayarak olumsuza karşı uyarma çabası olduğu bilinmelidir. Eleştirmenler sadece okurlara değil, yazarlara da bazı ipuçları sunma, ayna tutma ve anımsatma görevini üstlenirler. $\mathrm{Bu}$ nedenle eleştirmenlerin okurlarına karşı sorumluluğu eleştirel inceleme yazılarında büyük önem kazanmaktadır. Çünkü eleştirinin konusu bir sanat ürünüdür ve eleştirmen sanat eserini değerlendirip, onun üzerine düşünce üreterek okura ulaşmasında aracılık yapmaktadır. $\mathrm{Bu}$ aracılığı yaparken eleştirmen okuma biçimlerinden sadece bir tanesini örnek olarak sunmakta olduğunun bilincindedir. Çünkü her okur gibi her eleştirmen okuduğundan farklı anlamlar çıkarmakta özgürdür. Edebiyat eserleri her zaman farklı yorumlara açıktır. Bu yoruma açık olmaya Peter V. Zima şöyle bir örnek verir:

Edebiyat teorisyenlerine göre, ilmi metinlerin de çok anlamlılığı kaçınılmaz bir gerçektir. Bu bakımdan teorisyenler, edebi metnin manasının ne olduğu sorusunu unutma konusunda iyice kışkırtılmışlardır. Milton'un Kayıp Cennet veya Kafka'nın Duruşma başlıklı eserleri üzerine binlerce yorum yapılmıştır. Bütün bu yorumlardan sonra, bu metinlerin manasını sabitleştirmenin imkânsızlığı açıkça görülmüştür (Zima, 2004: 275).

Verilen alıntıdan da anlaşılacağı gibi, eserlerin farklı yorumlanması hiçbir zaman sona ermeyecektir ve her bir eleştirel inceleme eleştirmenin o anki kişisel algılaması ile yakından ilgilidir. Ne kadar nesnel davransalar da eleştirel incelemeler eleştirmenlere üç yanlı bir sorumluluk yüklemektedir. Eserin yazarına ve hitap ettikleri okura karşı sorumlu olmalarının ötesinde, bir de kendilerine karşı da sorumludurlar. Etki altında kalmayan ve önyargıda bulunmayarak doğru bildiğini söyleyebilen bir eleştirmen olmak kolay değildir. Eleştirmen eleştirel inceleme yazılarında yanılıyor, yanlış düşünüyor olabilir ve dolayısıyla değerlendirmesi de yanlış olabilir, ancak yine de bu nabza göre şerbet verme ve ikiyüzlü davranma kadar da kötü değildir. 
Arak, H. / Sosyal Bilimler Araştırmaları Dergisi. 2, (2007): 126-137

\section{Sonuç}

Eleştirmenlerin incelemelerine konu olan edebiyat eserinin öncelikle eleştirmen tarafından çözümlenecek, yorumlanacak bir estetik nesne olarak kabul edilmesi gerekir. Sanatçıların ortaya koydukları yeni eserlerin gizli kalmış yanları eleştirmenlerin eleştirel incelemelerinden oluşan ikincil yazınla birlikte ortaya çıkar. Eleştiriler sanatçının eserinin içeriğine yönelik irdeleme amaçlı olmalıdır. Sanatçının sahip olduğu dünya görüşü ve sanatı eleştirmene göre ne kadar değersiz olursa olsun, eleştirmen sanatçının kişiliğiyle değil eseriyle bir hesaplaşma içine girmelidir. Edebiyat eseri ile ilgili eleştiriler estetik alanla sınırlı kalmalı ve sanatçının kişiliği ile alay etme, onu küçümseme, yerle bir etme noktasına varmamalıdır. Bu nedenle de topluma karşı sanatçılar ne kadar sorumluysalar, eleştirmenler de hem topluma, hem de sanatçıya karşı o kadar sorumludurlar. Kaleme alınan eleştiriler olumlu, yapıcı ve sağlam dayanaklara sahip eleştiriyse, ona elbette herkes tarafından saygı duyulur. Böylece yapıcı eleştiri sayesinde sanatçı kendi eksikliklerini düzeltme olanağı bulur. Ama olumsuz kötü niyetli ve yıkıcı eleştiriyse o da hem okur hem de sanatçı tarafından önemsenmemelidir.

Edebiyat eserleri bir taraftan içerik ve biçim açısından irdelenip çözümlenirken, diğer taraftan yargılanırlar. Eserlere yönelik sanatsal, düşünsel değerlendirmeler yapılırken, estetik ölçütler yerine yazarların kişiliklerine yönelik geçersiz gerekçelere dayalı eleştiriye başvurulmamalıdır. Sanatçıların yazma eylemi bir dile geliş olarak değerlendirilirse, o zaman eleştiri de bu dile gelişin irdeleyicisi, değerlendiricisi ve çözümleyicisi olarak görülmelidir.

Yazın alanında eleştiri yazısı yazmak hiç kolay olmasa da bu alanda etkinlik gösteren kişinin de eleştiriyi göze alması gerekir. Daha başlangıçta eleştirmen bir taraftan okurlarına yararlı olmaya çalışırken, diğer taraftan hakkında eleştirel yazı yazdığı sanatçılarla karşılıklı tartışmalara, atışmalara girmek zorunda kalabilir. Yine de eleştirmen sanat adına yarar sağlamayacak bu tür kavgalardan uzak durmalıdır. Eleştirmenlerle sanatçılar arasında ortaya çıkacak olan bir kopukluk, iletişimsizlik okurları da etkileyecektir.

Eleştirmenler yerleşik sanat anlayışına uymayan, ya da eski değerleri altüst eden yeni sanat anlayışlarına tepkisiz ve vurdumduymaz kalmamalıdırlar. Kendi görüşlerini okurlarıyla paylaşmalı, onları bu konularda bilgilendirmeliler. Böyle bir yaklaşımdan, eleştirmen tutumundan yine en çok okurlar ve sanatçılar yarar sağlayacaklardır. Okuru ve sanatçıyı olumlu yönde geliştirmeye yönelik 
olarak kaleme alınan yazıların değeri biçilemeyeceği gibi, eserleri karalayıcı, yok sayıcı, hırçın bir söylemle yazılmış yazılardan da hiçbir yarar beklenmemelidir. Bu tür yok etmeye, yerle bir etmeye yönelik yazıların okurlara bir yararı olmadığı gibi, kalıcıllığı da yoktur ve zararı yalnızca yazıyı yazan eleştirmene ve okura verir. Eleştirmenlerin görevinin yeni bir sanat eseri ortaya koymak değil, ele aldığı eseri her yönüyle inceleyerek okurlarına tanıtmak olduğu bilinmelidir. İkincil yazını oluşturan eleştiri yazıları yazareleştirmen-okur üçgeninde her üçü için büyük önem taşımaktadır.

\section{Kaynakça}

\section{Kitaplar}

Aytaç, Gürsel. (1991), Edebiyat Yazlları II, Ankara: Gündoğan.

Aytaç, Gürsel. (1995), Edebiyat Yazıları III, Ankara: Gündoğan.

Belge, Murat. (2003), Eleştiri. (Soruşturma), Hece, Sayı 77/79, Ankara: Hece.

Carlaui, J. C.- J. C. Fillox, (1985) Edebi Eleştiri, (çev. A.H. Çakmaklı), Ankara: Kültür ve TBY.

Eagleton, Terry. (2004), Edebiyat Kuramı (çev: T. Birkan), İstanbul: Ayrıntı.

Moran, Berna. (1999), Edebiyat Kuramları ve Eleştiri, 2. Baskı, İstanbul: İletiş̧im.

Tural, Sadık. (1993), Edebiyat Bilimine Katkılar. Ankara. Ecdâd

Uçan, Hilmi.(2003), Edebiyat Bilimi ve Eleştiri. Ankara: Hece.

Uçan, Hilmi. (2006), Yazınsal Eleștiri ve Göstergebilim. 2. Baskı, Ankara: Hece.

Zima, Peter V. (2004), Modern Edebiyat Teorilerinin Felsefesi. (çev. M. Özsarı), Ankara: Hece.

\section{Dergiler}

Cumhuriyet Kitap: 25 Mayıs 1990, sayı: 15.

Cumhuriyet Kitap: 27 Haziran 1991, sayı: 70.

Cumhuriyet Kitap: 13 Ocak 1994, sayı: 202.

Cumhuriyet Kitap: 9 Mart 1995, say1: 264.

Varlık: Ocak 2000, say1: 2000/01-1108. 